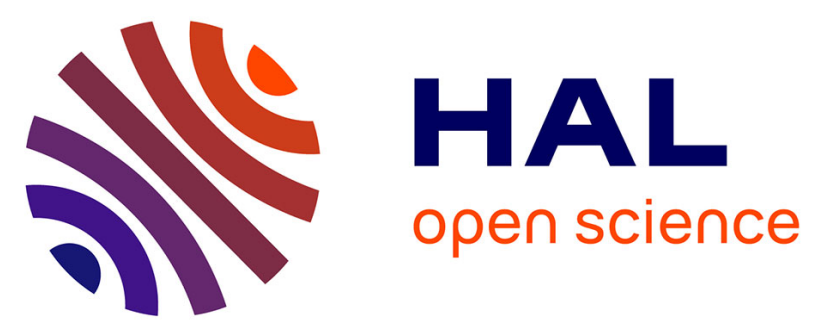

\title{
Rainwater harvesting to control stormwater runoff in suburban areas. An experimental case-study
}

Guido Petrucci, José-Frédéric Deroubaix, Bernard de Gouvello, Jean-Claude Deutsch, Philippe Bompard, Bruno Tassin

\section{- To cite this version:}

Guido Petrucci, José-Frédéric Deroubaix, Bernard de Gouvello, Jean-Claude Deutsch, Philippe Bompard, et al.. Rainwater harvesting to control stormwater runoff in suburban areas. An experimental case-study. Urban Water Journal, 2012, 9 (1), pp.45-55. 10.1080/1573062X.2011.633610 . hal00698564

\section{HAL Id: hal-00698564 \\ https://hal-enpc.archives-ouvertes.fr/hal-00698564}

Submitted on 7 Dec 2012

HAL is a multi-disciplinary open access archive for the deposit and dissemination of scientific research documents, whether they are published or not. The documents may come from teaching and research institutions in France or abroad, or from public or private research centers.
L'archive ouverte pluridisciplinaire HAL, est destinée au dépôt et à la diffusion de documents scientifiques de niveau recherche, publiés ou non, émanant des établissements d'enseignement et de recherche français ou étrangers, des laboratoires publics ou privés. 


\title{
This article has been published in: Urban Water Journal, Vol. 9(1), 2012 Rainwater harvesting to control stormwater runoff in suburban areas. An experimental case-study.
}

\author{
Guido Petrucci $^{\mathrm{a}, *}$, José-Frédéric Deroubaix ${ }^{\mathrm{a}}$, Bernard de Gouvello ${ }^{\mathrm{a}, \mathrm{c}}$, Jean-Claude Deutsch ${ }^{\mathrm{a}}$, \\ Philippe Bompard ${ }^{\mathrm{b}}$ and Bruno Tassin ${ }^{\mathrm{a}}$
}

\begin{abstract}
${ }^{a}$ Laboratoire Environnement Eau Systèmes Urbains (Leesu), Université Paris Est, AgroParisTech, UMR MA102. 6-8 avenue Blaise Pascal, 77455 Champs sur Marne cedex 2; Conseil général du Val-de-Marne, Direction des Services de l'Environnement et de l'Assainissement (DSEA). 2, avenue des Violettes, ZAC des Petits Carreaux, 94385 Bonneuil-sur-Marne Cedex ; ${ }^{c}$ CSTB (Centre Scientifique et Technique des Bâtiments).

* corresponding author : guido.petrucci@leesu.enpc.fr
\end{abstract}

\begin{abstract}
On a 23 ha urban watershed, $10 \mathrm{~km}$ East of Paris, rainwater tanks have been installed on $1 / 3$ of the private parcels to prevent stormwater sewer overflows. This paper investigates the macroscopic effect of rainwater harvesting on runoff, and thus the potential of this technique for stormwater source control. The analysis is performed using the SWMM 5 model, calibrated on rainfall- runoff measures from two measurement campaigns, before and after the equipment. The availability of two data-sets allows to point out changes in the catchment's behaviour. The main findings are that: (1) catchment's evolution, mainly caused by individual land-cover modifications, produces non-stationarity of the hydrologic behaviour; (2) the rainwater tanks installed, although they affect the catchment hydrology for usual rain events, are too small and too few to prevent sewer overflows in case of heavy rain events.
\end{abstract}

Keywords: rainwater harvesting; source control; BMP; runoff; rainfall-runoff analysis; sewer overflows

\section{Introduction}

Today, problems of urban runoff excess are addressed not only through traditional systems but also through stormwater "source control" (SC). Traditional systems, like sewer networks and downstream detention basins, concentrate stormwater from the catchment before managing it. SC, on the opposite, tries to manage small quantities of rainwater, as close as possible to its falling point, through small devices to store and/or to infiltrate it. These devices, widely known as Best Management Practices (BMP), are distributed over the catchment (Chocat, 1997).

A posteriori design of SC (i.e. on previously urbanised area) is rather difficult as, on the one hand, the available public areas are seldom and, on the other hand, installing SC on previously occupied private lots needs the final acceptance of the present owners (Marsalek and Chocat, 2002). Moreover, SC design requires not only a good knowledge of the hydrologic behaviour of the catchment, but also the capacity to forecast the urban planning of the area. Appropriate hydrologic models may be used to combine these different aspects and test the impact on runoff of different SC alternatives. Nowadays, this is successfully applied for BMPs' design or project, at the building or housing estate scale, but we still miss reliable tools and procedures for largescale planning (Niemczynowicz, 1999, Bethany, 2006, Chang et al, 2009).

Rainwater Harvesting (RH) is an ancient reviving practice. The possibility i) to reduce potable water consumption, ii) to reduce the water uptake outside of the catchments, iii) to participate to the restoration of the local water balance makes it sustainable. $\mathrm{RH}$ is not only diffusing in arid and semi-arid climates, but also where water shortages are extremely rare, like in northern France (de Gouvello, 2005), where it is often considered as a symbol of environmental involvement. From a SC point of view, rainwater tanks work as BMPs: during 
storm events, they fill up and store part of the rainfall. This water is definitely abstracted from the runoff component of the water cycle and used for local external or internal consumption.

However, two relevant characteristics distinguish rainwater tanks from usual BMPs: the direct advantage to the owner and the uncontrolled available capacity. The fact that the landowner takes advantage from the rainwater tanks makes this practice suitable in all the situations where it is not possible to oblige him to install a classical BMP on his property. This is in general the case for areas which are already completely urbanized and which experience stormwater management problems. Installing or subsidizing rainwater tanks can frequently represent one of the few SC options available.

The second characteristic is that water abstraction from the tanks is not controllable, as it is demand-driven. Then, the available rainfall storage capacity for a given rain event is even more uncertain for rainwater tanks than for usual BMPs. Moreover, the only collection surfaces are roofs, which represent a quite small fraction of land occupation in detached housing areas, where $\mathrm{RH}$ is better suited. This disadvantage causes a limited efficiency of rainwater tanks in reducing runoff.

Recently, experimental balances of $\mathrm{RH}$ have been studied at the building scale (de Gouvello et al, 2005, Kyoungjun and Chulsang, 2009); theoretical and modelling approaches have been used to quantify the effects on runoff (Guillon et al, 2008 ; Vaes et Berlamont, 2001); at the catchment scale, assessments have been done extrapolating small scale data (Coombes et al., 2002). To our knowledge, there is no analysis of macroscopic real-scale experimental results on runoff effect of stormwater tanks.

This paper presents a hydrological analysis based on a case study, where a significant number of rainwater tanks have been installed on the private parcels of a district, to prevent stormwater sewer overflows. Two rainfall-runoff measurement campaigns have been conducted before and after the tanks' installation, enabling the assessment of the effect of the tanks on runoff. The purpose of the analysis is to verify if $\mathrm{RH}$ is able to significantly reduce sewer overflows in the district. Moreover, the analysis points out that the catchment undergoes slow but sensible changes in its land cover and occupation, with hydrological consequences, even if no major change in the urban structure took place in the period considered.

\section{Material and methods}

\subsection{Methodology}

In this research, all the available data about the case-study catchment and its hydrological response are integrated in a rainfall-runoff model. To point out the evolution of the catchment's hydrological behaviour, an approach is to calibrate the model separately before and after the tanks' installation, using the two available data-sets from the measurement campaigns. In this way, evolutions in the catchment behaviour can be traced by differences in the model parameters and can be analyzed through model's simulations.

However, as the model relies on a large set of parameters, two completely independent calibrations will result in a large set of hardly interpretable differences. In order to generate through calibration two comparable sets of parameters, it is possible to define a limited number of parameters that can represent catchment's evolution. The selection of these parameters is made on the basis of available data's analysis (section 3), to depict expected or observed evolutions of the catchment.

The first step of this approach is to calibrate the whole model on one of the two data-sets. Then, a second calibration is done on the second data-set, but only for the few parameters selected. The results of this procedure are two calibrated models, one for each data-set, differing only for a limited set of physically interpretable parameters (par. 4.1). Comparisons between the two models can be done both on parameters' value (par. 4.2) and through simulations. To assess the impact of RH tanks on sewer overflows, simulations are focused on rain events likely to produce failures of the sewer system. Both real rainfall records (par 4.3) and synthetic hyetographs of given return periods (par 4.4) are used for the analysis. 


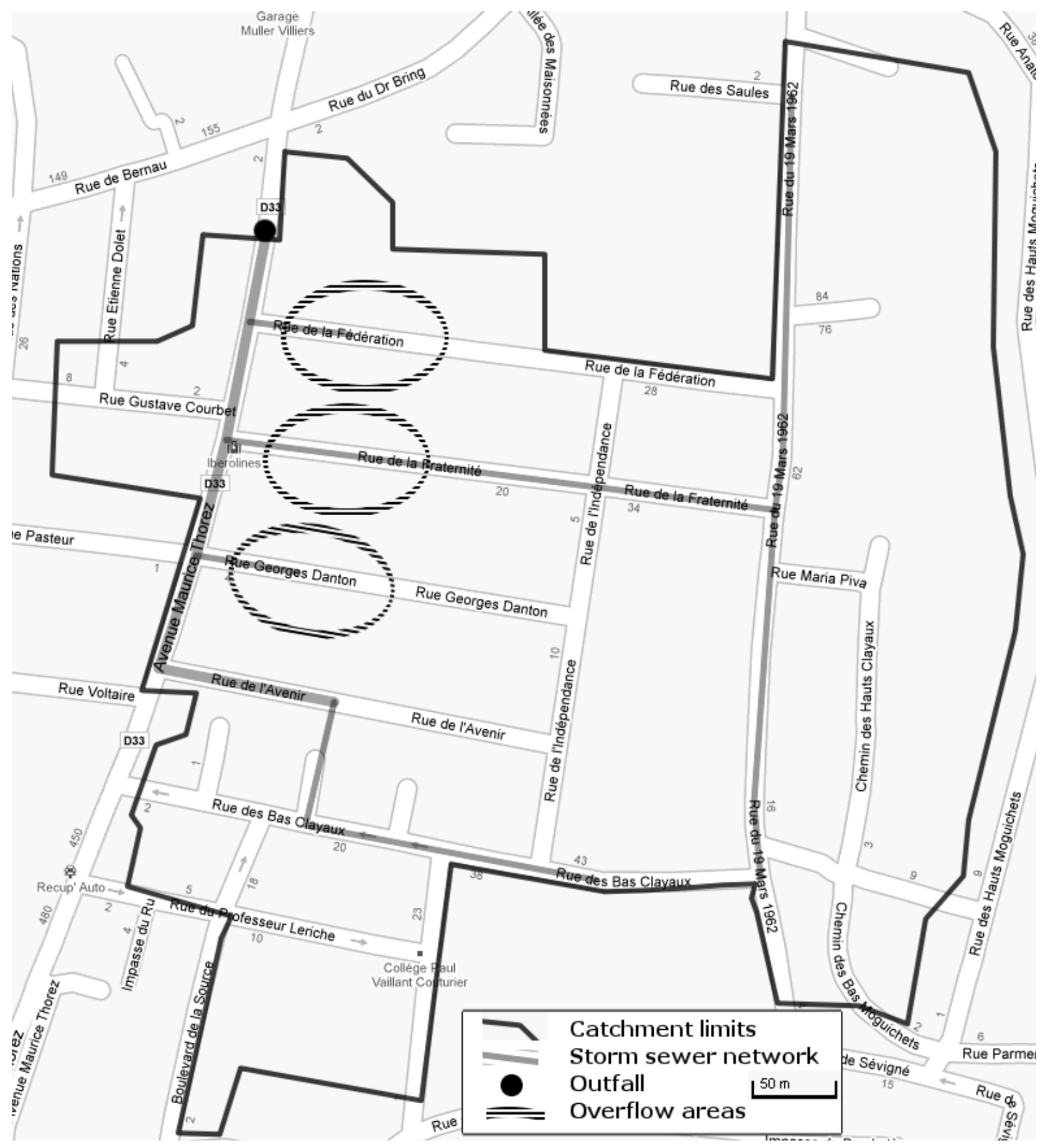

Figure 1 - Plan of the "Village Parisien", with catchment limits and stormwater sewer.

\subsection{Description of the district and of the experimentation}

The "Village Parisien" is a district occupied mainly by detached housing, in the city of Champigny-sur-Marne, $10 \mathrm{~km}$ east of Paris (France). The current urban development dates back to the 70's, and corresponds to the demolition of an adjacent slum (1971). The parcels have an average size of about $400 \mathrm{~m}^{2}$; they host private houses, parking areas and/or garages. The remaining parcels' surface is generally used for ornamental gardens. Most of the population is newly urban, and has a developed water awareness.

The catchment area corresponding to the district is 22.9 ha (figure 1), with a maximum length of $750 \mathrm{~m}$ and an average slope of $2 \%$. 
The sewer system is separate. The main collector $($ diameter $\mathrm{D}=0.8 \mathrm{~m}$, average slope $=$ $1 \%$ ) borders the Eastern side of the catchment, under the avenue Thorez. This avenue, and then the collector, does not follow the topographic thalweg of the catchment, which lies 50-100 m to the East. The streets perpendicular to the avenue Thorez are equipped with smaller collectors $(0.3 \mathrm{~m}<\mathrm{D}<0.6 \mathrm{~m})$ which feed the main one. The final segments of these secondary collectors, link the lowest points of the catchment to the main collector, and have very small slopes $(\approx 1 \% o)$. For this reason, in case of intense rain events, water overflows over the road surface in these lowest points.

Inhabitants reported overflows (up to $0.4 \mathrm{~m}$ over the road level) for intense storms in 2001 and 2007. The storm of the 25th of May 2007 was classified as an event with a return period between 5 to 10 years.

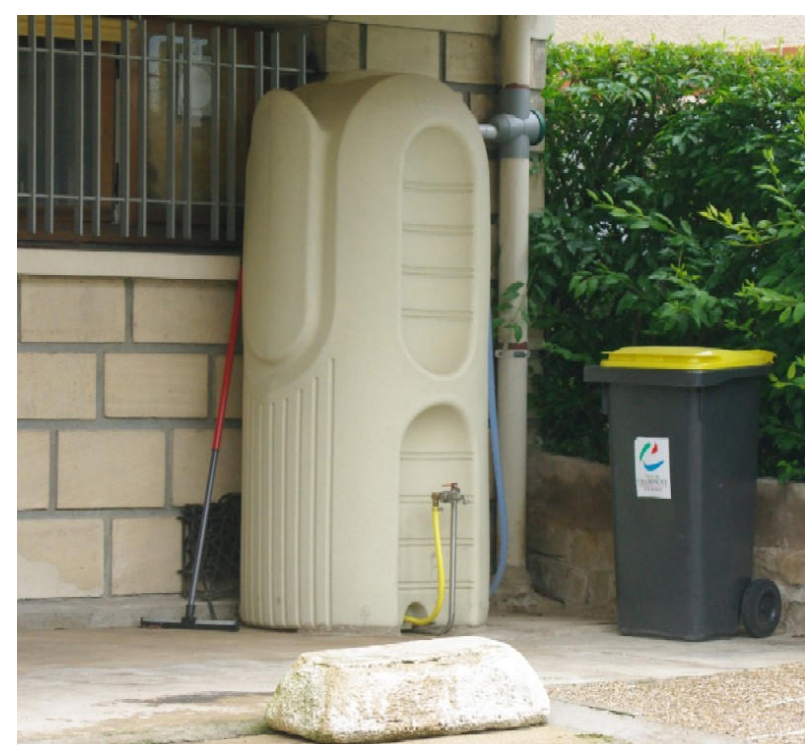

Figure 2 - A rainwater harvesting tank installed by the DSEA.

The environment and sewer service of the county (Direction des Services de l'Environnement et de l'Assainissement du Valde-Marne, DSEA) decided, also because of the limited flooding consequences, to experiment SC instead of classical pipe-based techniques (enlarging or doubling the sewer, etc.). Thus, DSEA installed for free RH tanks (figure 2) to a group of volunteers in the district. The tanks are external, with a size of $0.6 \mathrm{~m}^{3}$ or $0.8 \mathrm{~m}^{3}$. Each volunteer could choose size and number of the tanks (1 or 2$)$. The main expected use for the harvested water is gardening.
At the end of the installation (spring 2008), 157 parcels out of approximately 450 were equipped, for a total volume of $173 \mathrm{~m}^{3}$.

To perform the current study, the DSEA provided two runoff time series in the sewer at a 5-minute time step, both measured during the summer period:

(1) from the $29^{\text {th }}$ of July to the $30^{\text {th }}$ of October 2005, before tanks' installation;

(2) from the $25^{\text {th }}$ of June to the $23^{\text {rd }}$ of October 2008, after the installation.

Rainfall series are available from a rain gauge $200 \mathrm{~m}$ South-East of the catchment, in place since the 29th of July 2005. Other data available are sewer and parcels cartography, a list of the equipped parcels, and two orthophotographs of the catchment, one taken in 1998, and the other in 2007.

\subsection{Model and calibration}

The model used to integrate the available data and perform the analysis is SWMM 5 (Rossmann, 2004). It is a widely diffused urban hydrology model, flexible and well suited to represent BMPs (Elliott and Trowsdale, 2007).

In SWMM 5, both rainfall-runoff transformation on subcatchments and flow in the sewer network are modelled.

Each subcatchment is considered as a non-linear reservoir, with an outflow equation given by the kinematic wave approach (Singh, 1988). The corresponding equations, whose terms are listed in table 1 , are:

$$
\begin{aligned}
& \mathrm{dV} / \mathrm{dt}=\mathrm{A}\left(\mathrm{p}-\%_{\text {imp }} \mathrm{i}-\mathrm{e}\right)-\mathrm{Q}(\mathrm{V}) \\
& \mathrm{Q}(\mathrm{V})=\mathrm{kW}^{-1}\left(\mathrm{~d}-\mathrm{d}_{\mathrm{p}}\right)^{5 / 3} \mathrm{~s}^{-1 / 2}
\end{aligned}
$$

Some of the parameters can be defined differently for the pervious and impervious parts of a unique subcatchment, in particular the surface characteristics dp and $n$.

It is worth to remark the role of initial losses: they constitute, for a given subcatchment, the amount of rainfall that can be stored on it before the beginning of the outflow. This parameter will be used to describe the tanks' effect on the roofs equipped with them (see paragraph 3.3). 
The SWMM 5 model performs routing in channels and pipes by numerical solution of De Saint-Venant 1-D equations, under dynamic wave assumption. Manning friction formula is used (Graf and Altinakar, 2000). In this equation, the Manning's n for conduits plays a role of "velocity factor", like the analogous parameter in equation 2. Even if this parameter affects the hydrograph shape, considering the size of the catchment and the corresponding length scale, it will mainly contribute in slowing down or accelerating the runoff. This is equivalent to a time translation of the hydrograph at the outfall.

The model calibration is performed through a genetic algorithm. This type of algorithm has been used on hydrologic models during the last 20 years (e.g. Franchini et al., 1998). For each calibration, the first two-thirds of the rain events of a data-set are used for the calibration itself, while the remaining one-third for validation. The data-set parts are always used as continuous time-series, and not as discontinuous collections of rain events. This approach allows the model to simulate the initial conditions for each rain event.

The objective function used in the optimization is the Nash-Sutcliffe criterion (Nash and Sutcliffe, 1970):

$$
\mathrm{N}=1-\sum_{\mathrm{t}}\left(\mathrm{Q}_{\mathrm{o}, \mathrm{t}}-\mathrm{Q}_{\mathrm{s}, \mathrm{t}}\right)^{2} / \Sigma_{\mathrm{t}}\left(\mathrm{Q}_{\mathrm{o}, \mathrm{t}}-\mathrm{Q}_{\mathrm{o}, \text { mean }}\right)^{2}
$$

(equation 3)

Where Qo,t and Qs,t are respectively the observed and simulated values at time $t$, and Qo,mean is the observations' mean value. This indicator, ranging from $-\infty$ to 1 , is higher for a more accurate model. A value of 1 denotes a model perfectly matching the observed data, while a value of 0 denotes a model as accurate as the observations' mean value. This criterion is well suited for applications, like the current one, where the focus is on instant flow values and not on integrated values (e.g. daily runoff volume).

A complementary robustness test was performed, based on calibrations on synthetic time series obtained by randomly mixing the rain events available. The results of this process are poorer (i.e.: lower Nash criteria) than using the actual time series, because the consequentiality of the rain events is lost. In fact, the model estimates the initial conditions for a rain event simulating the preceding dry period. For the actual time series, simulated dry periods correspond to the actual ones, providing a coherent estimation of initial conditions. Conversely, for the synthetic time series with randomly mixed events, dry periods do not correspond with actual ones and provide, thus, poorer estimations. However, the parameters obtained by these calibrations sensibly confirm the robustness of those obtained with the actual time series. In fact, in $70 \%$ of the test calibrations, resulting parameters' values are in a $\pm 10 \%$ interval around the ones obtained by calibration over the actual time series.

\section{Data analysis}

\subsection{Catchment land-use and evolution}

The catchment area has been analyzed through orthophotographs, maps analysis and direct observations. It has been divided in 5 land-use categories: roads, equipped roofs (i.e. with tanks), non-equipped roofs, green areas and "others" (see data in table 2).

A visual inspection of the two available orthophotographs (1998-2007) shows an evolution of land cover. Even if nearly no new houses have been built, there is a slight increase in impervious areas (private driveways, garages, terraces; see for instance figure 3 ). This imperviousness increase is quite surprising for an already urbanized area and is taken into account in the hypotheses setting (paragraph 3.3).

It is noticeable, in table 2 , that the "others" surface category covers $21 \%$ of the total catchment area. These unclassified surfaces represent a heterogeneous set of landuses. These areas are considered as partially paved (driveways, etc., parameterised like roads) and partially pervious (bare soil, etc., parameterised like green areas); partition, through the \%imp parameter, is object of calibration.

\subsection{Rainfall-runoff analysis}

Both measurement campaigns took place in summer. All the results presented here are therefore valid only for this season. This fact, however, does not reduce the interest of the study, as the rain events producing sewer overflows are concentrated in summer. In facts, storms in that region are typically shorter and more intense in summer than in other seasons 


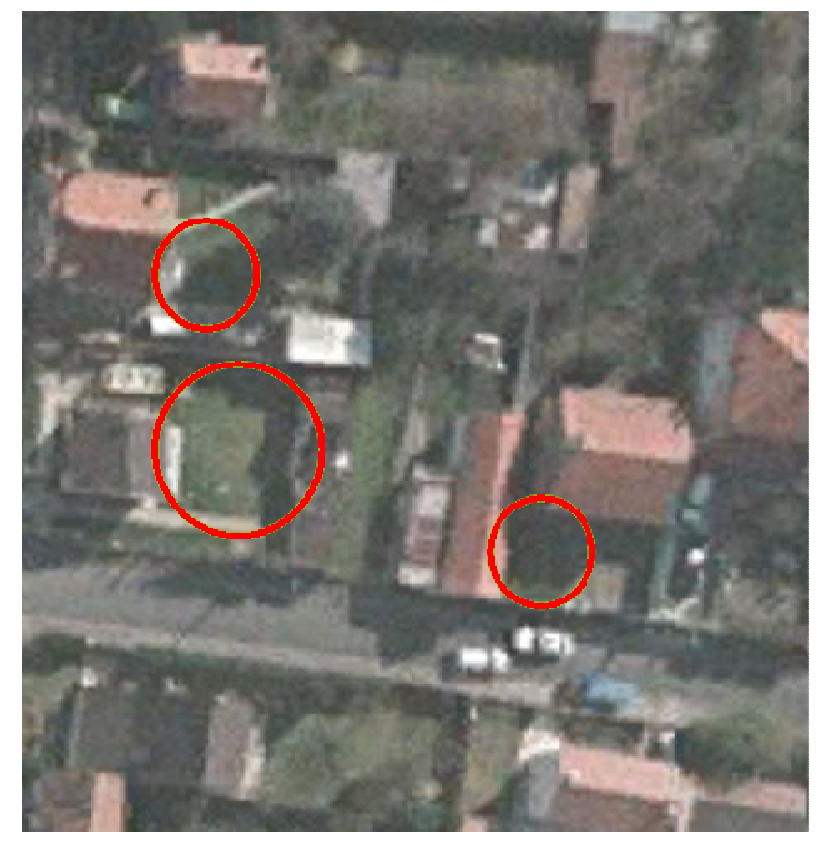

(a)

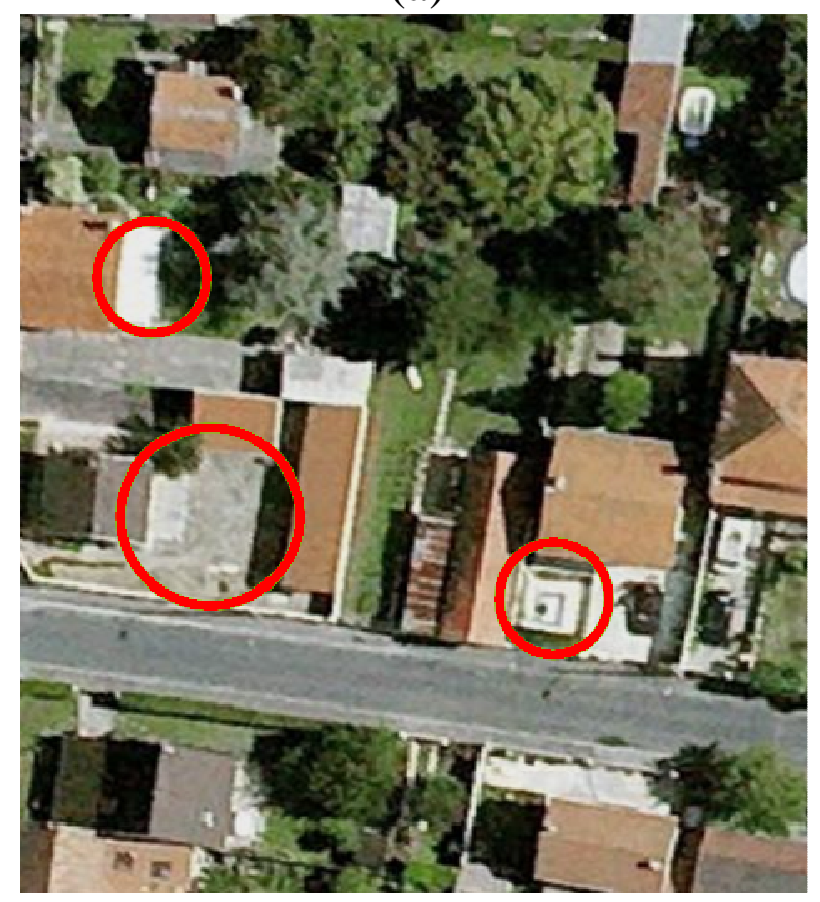

(b)

Figure 3 - Aerial views of a catchment detail in (a) 1998 and (b) 2007.

(Roux, 1996). The small size of the catchment makes this kind of rain event the more critical.

The hydrological conditions of the two campaigns are similar: the cumulative rainfall in the three months preceding the measurements where of $135 \mathrm{~mm}$ and $131 \mathrm{~mm}$ in 2005 and 2008 respectively.

The global runoff coefficient, estimated as the ratio of total runoff volumes and total rain volumes for $22.91 \mathrm{ha}$, is higher in 2008 than in 2005: 0.16 instead of 0.13.

An event-based analysis was conducted. Two rain events were considered separated if a period of 4 hours with less than $2 \mathrm{~mm}$ of precipitation occurred between them. 21 events were identified in 2005, 17 in 2008. This analysis shows that no heavy rainfall events occurred in 2005. The strongest rain in the 2005 recording period is the one of the 11th of September 2005, with a maximal average intensity on $30^{\prime}$ (I30') of $15.6 \mathrm{~mm} / \mathrm{h}$ and $\mathrm{I15} 5^{\prime}=$ $31.2 \mathrm{~mm} / \mathrm{h}$. In comparison, the rain event of the 7 th of August 2008 had I30' $=38 \mathrm{~mm} / \mathrm{h}$ and $\mathrm{I}^{\prime} 5^{\prime}=64.8 \mathrm{~mm} / \mathrm{h}$.

This absence of strong events in 2005 suggests to perform the complete calibration (paragraph 2.1) on the 2008 data-set, in order to obtain a parameter set based on a larger spectrum of events variability.

Figure 4 represents the distribution of the catchment's concentration time for the two data-sets. Even if the number of recorded events is too small to perform a significant statistical test, it seems that the concentration time increased between 2005 and 2008. This phenomenon can be interpreted in several ways. For example, it could be an effect of inlets and pipes obstructions, of the lengthening of flow paths in the catchment, or eventually of a bad synchronization between the rain gauge and the flow meter clocks. This effect is taken into account in the hypotheses setting (paragraph 3.3).

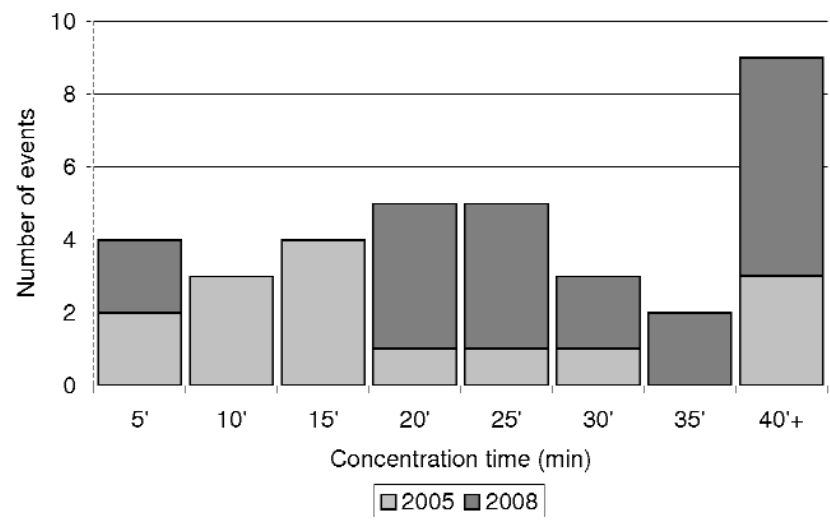

Figure 4 - Concentration time distribution for 2005 and 2008. 


\subsection{Hypotheses setting}

To analyse the evolution of the catchment in the 2005-2008 period, three hypotheses are made about the catchment change. They are based on changes both expected (tanks' installation) and observed in the available data (imperviousness increase and flow slowdown).

(1) Tanks' installation: the effect of this change is that, during rain events, the rainfall on equipped roofs does not produce runoff until the tanks are filled. The choice made is to transpose this effect in the model by a variation of the initial losses for equipped roofs areas. This choice is close to reality at the event-scale, because initial losses provide storage of rainfall until fulfilment. At a longer time-scale, however, this formulation can be less realistic: the abstraction from the tanks is, in fact, strongly simplified and described as a daily evaporation rate. This description of tanks will behave well only if the emptying time is generally shorter than the interval between two rain events.

In "Village Parisien", considering a specific average capacity of the tanks of $12.7 \mathrm{~mm}$ (see paragraph 4.2), a gardening surface double than the roof area, and a gardening demand of 2 $\mathrm{mm} /$ day, it is possible to estimate the actual emptying time in:

$\mathrm{T}_{\text {actual }}=1 / 2 \cdot 12.7 \mathrm{~mm} / 2 \mathrm{~mm} /$ days $=$

$$
=3.18 \text { days }
$$

The model simulates the abstraction as a monthly-based daily evaporation rate ranging between $1.9 \mathrm{~mm}$ (October) and $3.2 \mathrm{~mm}$ (July). The average over the simulation period is $2.63 \mathrm{~mm} /$ day. The model emptying time is:

$$
\begin{aligned}
\mathrm{T}_{\text {model }} & =12.7 \mathrm{~mm} / 2.63 \mathrm{~mm} / \text { days }= \\
& =5.04 \text { days }
\end{aligned}
$$

These two emptying times must be compared with the average dry period between two rain events. For the available time-series, $\mathrm{T}_{\mathrm{dry}}=6.16$ days. On first approximation, thus, at the beginning of a rain event both real and modelled tanks will be empty. The simple description chosen appears to be acceptable in the specific conditions.
The advantage of this description is that it does not require formulating any assumption on water demand, as the tanks are globally described by a single parameter, which could be calibrated.

(2) Imperviousness increase: the effect of this change is an increase in runoff volume, especially for small to medium rain events (i.e.: when pervious areas do not contribute significantly to runoff). This change, described in paragraph 3.1, does not concern roofs or roads but only driveways, terraces, etc. Thus, it is transposed in the model as a variation of the impervious area ratio for "other" areas.

(3) Flow slowdown: the effect of this change is a delay in the hydrograph. As explained in paragraph 3.2, this phenomenon is noticeable in the data and could be physically interpreted in different ways. The available information about the catchment is not sufficient to provide a reliable explanation of it. Then, the process is just translated in the model through a parameter having a similar effect: the Manning's $n$ for the pipes (see par. 2.3).

\section{Results and discussion}

\subsection{Calibration}

Table 3 shows the results obtained by the calibration process.

For 2008, the calibration was performed for the whole set of model's parameters. The Nash criteria values obtained, both in calibration and validation, are high $(>0.8)$ and confirm, thus, the capability of the model to represent correctly the catchment's observed behaviour.

The calibration on the 2005 data-set was performed on the three parameters (initial losses for equipped roofs, imperviousness ratio for "other" areas, Manning's $\mathrm{n}$ for pipes) described in paragraph 3.3. Also in this second case, Nash criteria values are high. The calibration value, however, is lower (0.59) than the other values obtained. This is linked to the first events recorded: the robustness test with random series showed that including these first events always produce lower Nash values. However, it showed also that the parameter 
estimated considering or not these events do not vary significantly. Thus, these "bad" events were kept anyway in the data-set: as the number of recorded rain events is small, it is more appropriate to use the highest number of events available. A likely explanation of this poorer quality is that the rain gauge was just installed.

\subsection{Analysis of catchment evolutions' effect}

Observing the parameters' variation obtained by the calibration (table 3 ), an interesting result is the variation on initial losses for equipped roofs. Considering the total storage volume available $\left(173 \mathrm{~m}^{3}\right)$ and the total equipped roofs' area $\left(13601 \mathrm{~m}^{2}\right)$, it is possible to estimate the maximum variation in initial losses (i.e.: if the tanks were always empty at the beginning of a rain event):

$$
\begin{aligned}
\mathrm{d}_{\mathrm{p}, \max } & =\mathrm{V}_{\text {tot }} / \mathrm{A}_{\text {tot }}=173 \mathrm{~m}^{3} / 13601 \mathrm{~m}^{2}= \\
& =12.7 \mathrm{~mm}
\end{aligned}
$$

The value obtained by the calibration $(11,3 \mathrm{~mm})$ shows that the observed effect of the tanks is about $90 \%$ of the maximum expectable effect. A reasonable conclusion is that in

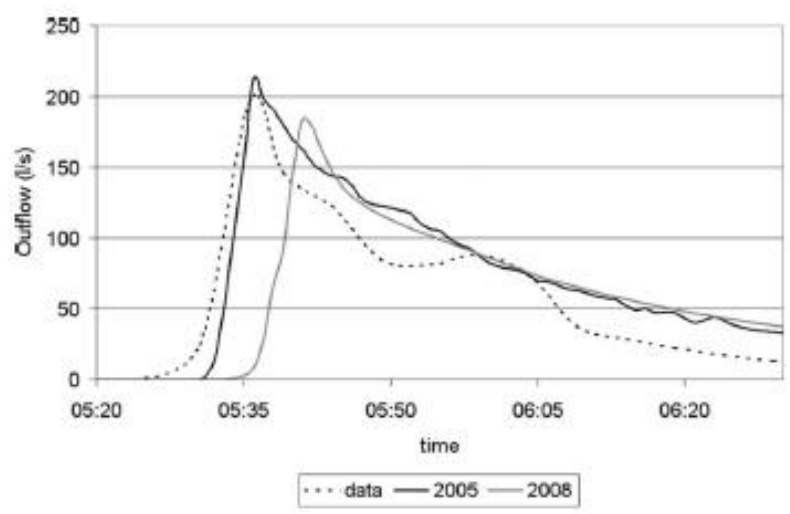

(a)

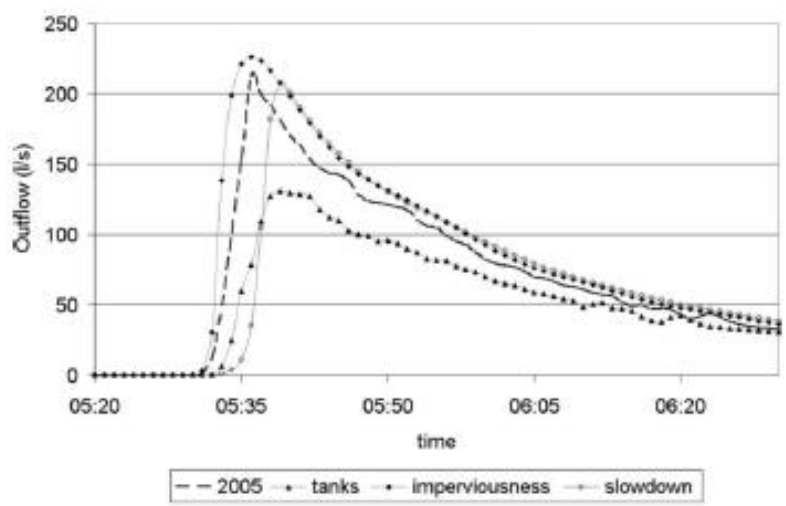

(b)

Figure 5. (a) Simulations of the model calibrated for 2005 and 2008 and (b) of the model calibrated for 2005 varying each parameter. Rain event of 21 October 2005. summer, when ornamental gardening demand is high and rain events infrequent, it is reasonable to assume that the tanks are empty at the beginning of the rain events.

To appreciate the relative effect of each of the three parameter's variations, the system is simulated for a given rain event $(21 / 10 / 2005$, total rainfall of $8.8 \mathrm{~mm}, \mathrm{I} 30^{\prime}=13.2 \mathrm{~mm} / \mathrm{h}$ ), with 2005 and 2008 values, and also with each parameter varying alone (figure 5). The overall behaviour change (peak attenuation and delay) between 2005 and 2008 is noticeable in graph a). The graph b) shows the strong attenuation effect of the rainwater tanks, and the opposite effect of the imperviousness increase.

\subsection{Sensitivity analysis to tanks installation}

To evaluate the efficacy of the tanks in reducing sewer overflows, the simulations of two rain events, one small $(21 / 10 / 2005,8.8$ $\mathrm{mm}, \quad \mathrm{I} 30^{\prime}=13.2 \mathrm{~mm} / \mathrm{h}$ ) and one large $\left(25 / 05 / 2007,31.6 \mathrm{~mm}, \mathrm{I} 30^{\prime}=44.9 \mathrm{~mm} / \mathrm{h}\right)$ are compared. During the latter, that has a return period between 5 and 10 years, overflows have been reported. Four different scenarios are

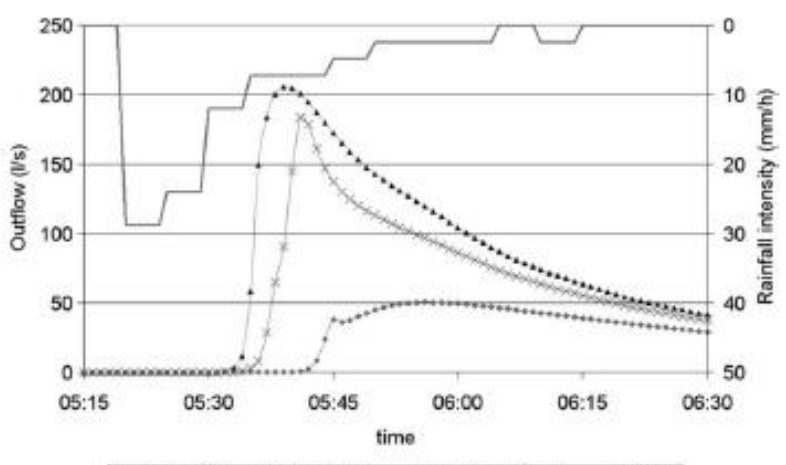

$\rightarrow$ tanks full $*$ tanks empty $\rightarrow$ all roofs oquippod - rainfall

(a)

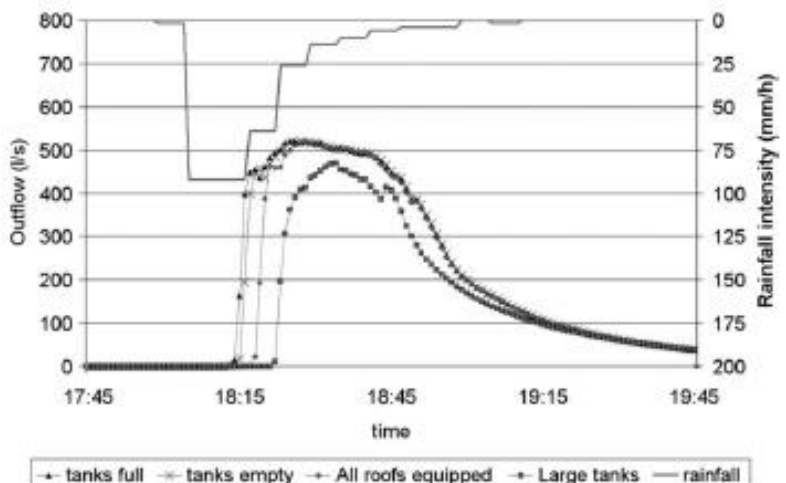

(b)

Figure 6. Scenarios' simulations for the rain events (a) of 21 October 2005 and (b) of 25 May 2007. 
considered:

(1) All the tanks are full. This scenario is equivalent to the absence of tanks.

(2) All the tanks are empty. This scenario is the most favourable under the present equipment: the initial losses increase on equipped roofs is set to $12.7 \mathrm{~mm}$.

(3) All the roofs are equipped with empty tanks (volume limited scenario). This scenario is intended to show the maximal effect of this size of tanks on the considered catchment. An initial losses increase of $12.7 \mathrm{~mm}$ is applied to all the roofs of the catchment.

(4) All the roofs are equipped with "large" tanks, i.e. all the roofs are disconnected from the sewer (harvesting surface limited scenario). This scenario is intended to test the potential effect of larger tanks on runoff. It tests, more generally, if it is possible to avoid sewer overflows through actions on the roofsgenerated runoff alone. It is then simulated only for the largest rain.

Simulations are shown in figure 6. For the small rain event (a), a consistent reduction

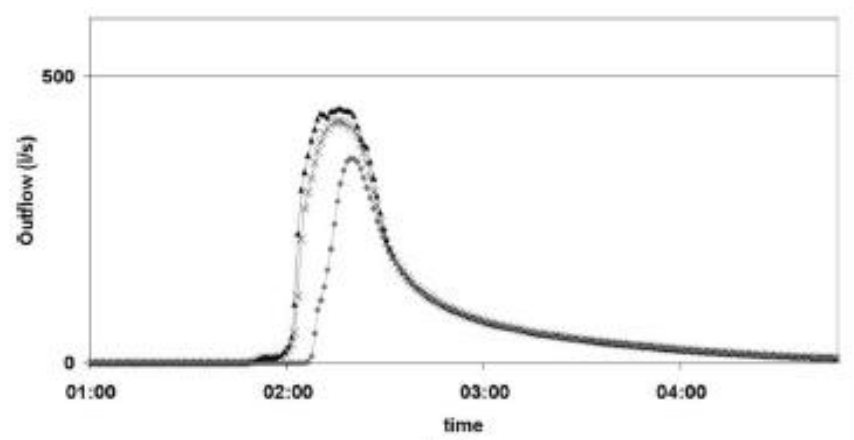

(a)

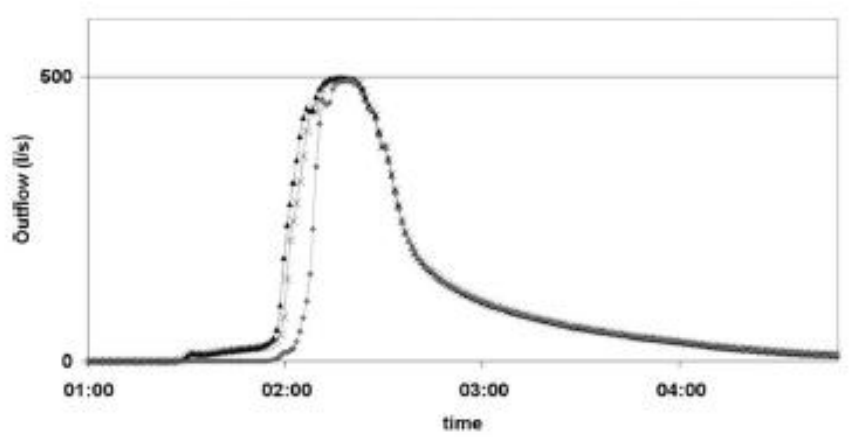

(c) in runoff is obtained with the current equipment when the tanks are empty. It is possible to obtain further consistent reduction of runoff through the equipment of other roofs.

For the strong rain event (b), the situation changes: the rainfall exceeds the tanks storage capacity (scenarios 1 to 3 ) and even the infiltration capacity of the soil (i.e.: pervious areas contribute to runoff). In that case the tanks' effect on runoff is negligible: passing from the first to the third scenario, the peak flow is just shortened of a few minutes, and then the trajectories are superposed. The peak flow is not reduced.

However, in the fourth scenario the hydrograph peak is reduced of about $10 \%$. This is enough to make it lower than $0.5 \mathrm{~m}^{3} / \mathrm{s}$, which can be considered as an overflow threshold. Even if this scenario is extreme and, probably, unfeasible, this simulation shows that it is theoretically possible to avoid sewer overflows (for the considered rain event) acting just on roofs-generated runoff.

\subsection{Sensitivity analysis to return period}

The analysis showed that, for the rain-event considered, the actual equipment is rapidly

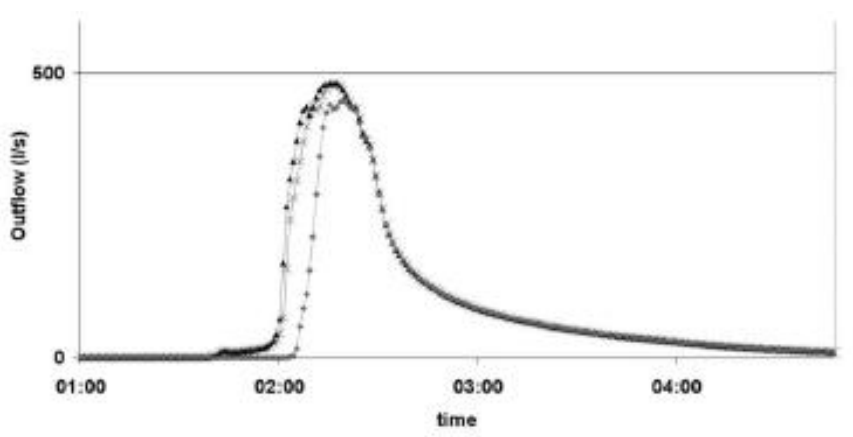

(b)

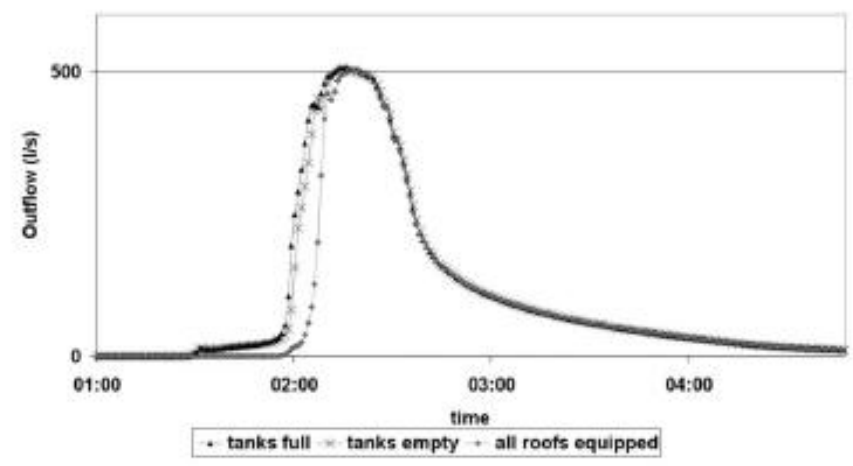

(d)

Figure 7. Scenarios' simulations for synthetic rain events of increasing return period, (a) 2 years, (b) 3 years, (c) 4 years, (d) 5 years. 
ineffective. The cause is that, with increases in the rainfall, the effect of rainwater tanks is progressively reduced. It is interesting to verify if, in the "Village Parisien" case, the effect of the actual equipment is sufficient to avoid sewer overflows for at least some rain-events.

Then, it is possible to consider a set of increasing return periods (from 2 to 5 years) for a given duration (30 minutes) and the corresponding synthetic hyetographs (double triangle hyetographs, widely used in France (Desbordes, 1974)). Intensities are based on the Paris-Montsouris weather station I-D-F curves. The simulations of the first three scenarios described above are presented in figure 7.

With increasing return period, tanks' effect becomes smaller, while peak flow rate increases. Let's consider the overflow threshold of $0.5 \mathrm{~m}^{3} / \mathrm{s}$. For the two smaller rains, the threshold is not reached by any scenario. For a 1-in-4-years rain (c), the threshold is reached by both the full and empty scenarios, while the hydrograph for the complete equipment scenario is barely under it. For a 1-in-5-years rain (d), the three scenarios reach the threshold.

In conclusion, the effect of the existing tanks becomes negligible for a 1-in-3-years rain event, too small to produce any overflow. The current equipment is then ineffective in avoiding any overflow in the district. An equipment of all the parcels of the catchment with rainwater tanks analogous to the ones actually in use will not improve results significantly.

\section{Conclusions}

In the case study discussed in this article, a consistent number of rainwater harvesting tanks was distributed in an urban catchment in order to avoid sewer overflows. About $30 \%$ of the roofs in the catchment were equipped with an average specific capacity of $12.7 \mathrm{~mm}$. The analysis is based on two rainfall-runoff measurement campaigns, and performed using the SWMM 5 model. The main purpose of the analysis is to evaluate, on a real-scale experimental setting, the impact of $\mathrm{RH}$ on runoff.

The data analysis shows that the catchment undergoes significant evolutions despite its urban characteristics did not change. A model setting and calibration methodology were then developed to compare both the catchment evolution and the tanks installation.

Catchment evolutions, and in particular diffuse imperviousness increase, have similar but opposite hydrological effects than the tanks' installation, even on the short period considered (3 years). The consequences on SC practices and planning are relevant:

(1) The time-scales involved in the evolution of urban catchments are small, also when no major changes occur. Using old data about a catchment without any updating procedure involves a risk.

(2) Symmetrically, CS planning must take into account the physical and urban context as a dynamical variable, especially on long term scenarios.

About the impact of RH tanks on runoff, the results show that the equipment installed on the "Village Parisien" is not able, alone, to prevent any stormwater sewer overflow. Its effect on runoff, in facts, become negligible for rain events smaller than the ones generating sewer overflows.

Another finding is that the inefficacy of the equipment is linked to the tanks' volume and not to the harvesting area: according to simulations, installing the same size of tanks on every parcel of the catchment will not provide better results. On the contrary larger tanks, at least theoretically, could prevent overflows for rain events with return period between 5 and 10 years.

It is important to point out that $\mathrm{RH}$ is considered as the only SC technique applied in the catchment. Even if, alone, this technique proved to be ineffective without large investments (i.e. large tanks in all the parcels), in practice it could be usefully integrated in a series of cascading BMPs installed both on private and public areas.

In conclusion, on an already developed urban catchment, rainwater harvesting subsidizing can prove to be a socially acceptable and reasonably-priced SC solution, but its hydrologic effectiveness can be poor without a wise planning and implementation. An effective solution needs to take into account both the parcel-scale and the catchment-scale. At the parcel-scale, this is possible through a balance of the ratios among tanks' volumes, 
roofs' areas and rainwater demand; at the catchment-scale, through an analysis of the different contributions to runoff.

\section{Acknowledgements}

The authors wish to acknowledge the support given by the Conseil Général du Val-de-Marne, and would like to thank particularly the DSEA for the precious help provided.

\section{References}

Chang, C., Lo, S. and Huang, S., 2009. Optimal strategies for best management practice placement in a synthetic watershed, Environmental Monitoring and Assessment, 153 (1-4), 359-364

Chocat, B. (ed.), 1997. Techniques alternatives. In: Encyclopédie de l'hydrologie urbaine et de l'assainissement, Eurydice 92, Lavoisier, Paris.

Coombes, P.J., Kuczera, G., Kalma, J.D. and Argue, J.R., 2002. An evaluation of the benefits of source control measures at the regional scale, Urban Water, 4 (4), 307-320

Desbordes, M. , 1974. Réflexions sur les méthodes de calcul des réseaux urbains d'assainissement pluvial. PhD Thesis, Université des Sciences de Montpellier.

de Gouvello, B., 2005. La récupération et l'utilisation de l'eau pluviale dans les bâtiments : état des lieux et des questionnements en France. Techniques Sciences et Méthodes, 2005-6, 73-79

de Gouvello, B., Berthineau, B., Croum, I. and François, C., 2005. L'utilisation de l'eau de pluie dans le bâtiment. Les résultats d'opérations expérimentales en France. Annales du Bâtiment et des Travaux Publics, juin 2005, 13-20

Elliott, A.H. and Trowsdale, S.A., 2007. A review of models for low impact urban stormwater drainage, Environmental Modelling \& Software, 22 (3), 394-405

Franchini, M., Galeati, G. and Berra, S., 1998. Global optimization techniques for the calibration of conceptual rainfall-runoff models. Hydrological Science Journal, 43, 443-458

Graf, W.H. and Altinakar, MS, 2000. Hydraulique fluviale: écoulement et phénomènes de transport dans les canaux à géométrie simple, PPUR presses polytechniques

Guillon, A., Kovacs, Y., Roux, C. and Sénéchal, C., 2008. Rain water reusing for watering purposes: what storage capacity is needed and what benefits for the sewer networks. In: 11th International Conference on Urban Drainage, Edinburgh, Scotland

Kyoungjun K. and Chulsang Y., 2009, Hydrological Modeling and Evaluation of Rainwater Harvesting Facilities: Case Study on Several Rainwater Harvesting Facilities in Korea, Journal of Hydrologic Engineering (ASCE), 14 (6), 545-561

Marsalek, J. and Chocat, B., 2002. International report: Stormwater management. Water science and technology, 46, 6-71

Nash, J.E. and Sutcliffe, J.V. 1970. River flow forecasting through conceptual models part I. A discussion of principles. Journal of Hydrology, 10, 3, 282-290

Niemczynowicz, J., 1999. Urban hydrology and water management - present and future challenges. Urban Water, 1 (1), 1-14

Rossmann, L.A., 2004. Storm water management model User's manual version 5.0. Cincinnati, OH: U.S. EPA, Water Supply and Water Resources Division, National Risk Management Research Laboratory

Roux, C., 1996. Analyse des précipitations en hydrologie urbaine. Exemple de la Seine-Saint-Denis. PhD thesis, CERGRENE, Ecole Nationale des Ponts et Chaussées, Paris

Singh, V.P., 1988. Hydrologic systems, Vol. I: Rainfall runoff modelling. Englewood Cliffs, NJ: Prentice Hall. 285-286

Vaes, G. and Berlamont, J., 2001. The effect of rainwater storage tanks on design storms. Urban Water 3, 303-307 
Table 1 - Terms of the subcatchment model

\begin{tabular}{|c|c|c|c|c|c|}
\hline Term & S.I. & Description & Ter & S.I. & Description \\
\hline $\mathrm{V}$ & $\mathrm{m}^{3}$ & $\begin{array}{l}\text { Volume stored over the } \\
\text { subcatchment }\end{array}$ & Q & $\mathrm{m}^{3}$ & Outflow \\
\hline A & $\mathrm{m}^{2}$ & Subcatchment area & W & $\mathrm{m}$ & $\begin{array}{l}\text { Average width of the } \\
\text { subcatchment }\end{array}$ \\
\hline $\mathrm{p}$ & $\mathrm{m}$ & Rainfall & d & $\mathrm{m}$ & Water level (V/A) \\
\hline$\%_{\text {imn }}$ & $\%$ & Impervious area ratio & $d_{n}$ & $\mathrm{~m}$ & Initial losses \\
\hline $\mathrm{i}$ & $\mathrm{m}$ & $\begin{array}{l}\text { Infiltration, estimated by } \\
\text { Green-Ampt model }\end{array}$ & $\mathrm{n}$ & / & $\begin{array}{l}\text { Manning's } n \text {, depending on } \\
\text { surface characteristics }\end{array}$ \\
\hline $\mathrm{e}$ & $\mathrm{m}$ & $\begin{array}{l}\text { Evapotranspiration, assumed } \\
\text { as a monthly constant }\end{array}$ & $\mathrm{s}$ & l & $\begin{array}{l}\text { Average slope of the } \\
\text { subcatchment }\end{array}$ \\
\hline
\end{tabular}

Table 2 - Catchment's surface analysis

\begin{tabular}{lllllll} 
& $\begin{array}{l}\text { Green } \\
\text { areas }\end{array}$ & Roads & Others & $\begin{array}{l}\text { Equipped } \\
\text { roofs }\end{array}$ & $\begin{array}{l}\text { Non-equipped } \\
\text { roofs }\end{array}$ & Total \\
\hline $\begin{array}{l}\text { Area } \\
\left(\mathrm{m}^{2}\right)\end{array}$ & 119896 & 22852 & 47701 & 13601 & 25050 & 229100 \\
\hline$\%$ & 52 & 10 & 21 & 6 & 11 & 100
\end{tabular}

Table 3 - Nash criteria and parameters' values from the calibration

\begin{tabular}{lccccc} 
& $\begin{array}{c}\text { Nash } \\
\text { (calibration) } \\
(-)\end{array}$ & $\begin{array}{c}\text { Nash } \\
\text { (validation) }\end{array}$ & $\begin{array}{c}\text { Init. losses } \\
\text { (equip. roofs) }\end{array}$ & $\begin{array}{c}\text { Imp. area ratio } \\
\text { ("others") }\end{array}$ & $\begin{array}{c}\text { Pipes" } n \\
(-)\end{array}$ \\
\hline 2005 & 0.59 & 0.81 & 2.76 & 2.6 & 0.02 \\
2008 & 0.84 & 0.83 & 14.06 & 13.4 & 0.03 \\
\hline Variation & - & - & +11.3 & +10.8 & +0.01
\end{tabular}

This document is an authors' version of the article:

Guido Petrucci, José-Frédéric Deroubaix, Bernard de Gouvello, Jean-Claude Deutsch, Philippe Bompard and Bruno Tassin. Rainwater harvesting to control stormwater runoff in suburban areas. An experimental case-study. Urban Water Journal, Vol. 9(1), 2012. 